Fecha de recepción: enero de 2018 Fecha de aceptación: marzo de 2018

Link para este artículo: http://dx.doi.org/10.14198/RHM2018.36.03

Puede citar este artículo como:

Fuertes BRoseta, Miquel, «L'estament militar de València i la notícia de l'expulsió dels moriscos», Revista de Historia Moderna. Anales de la Universidad de Alicante, n. ${ }^{\circ} 36$ (2018), pp. 84-113, DOI: 10.14198/RHM2018. 36.03

\title{
L'ESTAMENT MILITAR DE VALÈNCIA I LA NOTÍCIA DE L'EXPULSIÓ DELS MORISCOS ${ }^{1}$
}

\author{
MiQUEL FUERTES BROSETA \\ Università degli Studi di Cagliari-Universitat de València \\ miquelfuertesbroseta@gmail.com \\ https://orcid.org/0000-0003-4995-4860
}

\section{Resum}

A principis de setembre de 1609, els preparatius per a l'expulsió dels moriscos havien començat en secret i l'Estament Militar va començar a dubtar sobre ells. Després d'alguns dies i altres tants conflictes, la noblesa va decidir posicionar-se en contra de l'expulsió. Per aquesta raó, van enviar dos ambaixadors al rei per a explicar els motius pels quals pensaven que seria una mala decisió.

Aquest treball analitza el procés pel qual l'Estament Militar de València va decidir la seua posició sobre l'expulsió, el treball dels ambaixadors a Madrid, les raons de la noblesa per estar en contra de l'expulsió i com, finalment, la fidelitat i l'obediència van ser la decisió final.

Paraules clau: segle XVII, Regne de València, moriscos, expulsió dels moriscos, Felip III, ambaixada

1. Aquest treball s'ha realitzat gràcies a una beca predoctoral concedida per l'Ateneo de la Università degli Studi di Cagliari per al XXXIII cicle de doctorat. Així mateix s'insereix dins del projecte d'investigació Nuevas perspectivas de historia social en los territorios hispánicos del Mediterráneo Occidental durante la Edad Moderna (HAR2014-53298-C21-P) finançat pel Ministerio de Economía y Competitividad (MINECO). 


\section{El Estamento Militar de Valencia y la noticia de la expulsión de los moriscos}

\section{Resumen}

A principios de septiembre de 1609, los preparativos para la expulsión de los moriscos habían comenzado en secreto y, en consecuencia, el Estamento Militar comenzó a preguntarse sobre ellos. Después de algunos días y algunos conflictos, la nobleza decidió posicionarse en contra de la expulsión. Por esa razón, enviaron dos embajadores al rey para explicar los motivos por los que pensaban que sería una mala decisión.

Este trabajo analiza el proceso por el que el Estamento Militar de Valencia decidió su posición sobre la expulsión, el trabajo de los embajadores en Madrid, las razones de la nobleza para estar en contra de la expulsión y cómo, finalmente, la fidelidad y la obediencia fueron la decisión final.

Palabras clave: siglo XVII, Reino de Valencia, moriscos, expulsión de los moriscos, Felipe III, embajada

\section{The Military State of Valencia and the news about the moriscos' expulsion}

\section{Abstract}

At the beginning of September of 1609 the preparations for the moriscos' expulsion had started in secret and the Military State starts to ask about them. After few days and some conflicts, the nobility decided to position themselves against the expulsion. For that reason, they sent two ambassadors to the king for explain the motives why they thought it would be a bad decision.

This work analyses the process by the Military State of Valencia had decided his position about the expulsion, the work of the ambassadors in Madrid, the reasons of the nobility to be against the expulsion and how, finally, the fidelity and the obedience was the final decision.

Keywords: Seventeenth century, Kingdom of Valencia, military state, Moriscos, Moriscos' expulsion, Philip III, embassy

\section{Les Juntes d'Estaments valencianes}

Als territoris de la Corona d'Aragó l'actuació del poder reial contava amb el contrapès de les institucions representatives amb les quals havia de dialogar i pactar. El principal exponent d'aquest sistema eren les Corts, considerades principal escenari del pactisme, en les que es reunien rei i regne, aquest últim representat en el cas valencià per els tres braços: Eclesiàstic, Militar i Reial. 
No obstant, les Corts no estaven reunides permanentment i fora d'elles eren necessaris altres organismes que permeteren seguir mantenint el diàleg entre el monarca i els súbdits. Al Regne de València una d'aquestes institucions eren allò que la historiografia anomena Juntes d'Estaments.

En els últims anys l'interès per l'estudi d'aquestes Juntes s'ha desenvolupat al calor d'una disputa historiogràfica sobre si bé eren els Estaments o bé la Diputació qui assumien la representació del regne. A aquestes dos posicions, que va resumir ja fa algun temps Giménez Chornet, s'ha sumat fa uns pocs anys una tercera via en la que es situen autors com Isabel Lorite, Emilia Salvador o Lluís Guia. Aquests autors tenen en comú que proposen que atorgar representativitat a uns no implica necessàriament retirar-la als altres. Així mateix també coincideixen en fer una crida a noves investigacions que ajuden a esclarir aquest debat ${ }^{2}$.

En aquest treball no es pretén resoldre aquesta disputa historiogràfica, però sí que el podem situar en la línia de les noves investigacions que intenten aproximar-se al funcionament de les institucions forals valencianes ${ }^{3}$. Com veurem més endavant no podem parlar de representació de regne en el cas estudiat, doncs l'Estament Militar actuà en solitari i s'entén que la representació del regne requeia conjuntament en els tres Estaments ${ }^{4}$. No obstant, per

2. Giménez Chornet feu un estat de la qüestió sobre el tema en el que dividia als autors tant contemporanis com d'època en dos grups segons atribuïren la representació a una o altra institució, concloent l'article posicionant-se en favor de la postura estamentalista. GIMÉNEZ CHORNET, 18 (1992): 7-28.Per altra banda, la tercera via ha estat resumida ja per Isabel Lorite en la seua tesis doctoral, incloent-se ella mateixa en aquesta posició. No obstant exclou d'aquesta posició a Lluís Guia, a qui Chornet situa en la posició estamentalista però que caldria situar en aquesta tercera. Doncs, segons Guia «caldria relativitzar la dicotomia Diputació versus Juntes d'Estaments donat que tot plegat mantenien una estreta correspondència». GUIA MARÍN, 10-11 (2001-2002): 909, nota 79. LORITE MARTínEZ, 2015: 596. SALVAdOR ESTEBAN, 2004: 374.

3. Per donar alguns exemples referim els treballs d'Isabel Lorite, José María Castillo o Oscar Clavell. LORIte MartíneZ, 2015; Castillo del CARPIO, 2013 i Clavell LóPez, 2016.

4. Mateu i Sanz defenia que «todos los honores y preeminencias que pertenecen al Reino fuera de cortes les tocan y las gozan los tres Estamentos que le representan», de la qual cosa s'entén que la representació del regne recau en la suma del tres Estaments.

Per a Mateu, Braç i Estament «en realidad es un mismo gremio que componen las mismas vozes o sugetos, congregados legitimamente en Cortes se llama Braço y fuera de Cortes Estamento». Pel que respecta a l'Estament Militar, encara que teòricament podien acudir 
aquesta raó no deixa de ser interesant l'estudi de l'activitat d'aquest Estament, sobre tot la relacionada amb un succés tan transcendental com l'expulsió dels moriscos en el que alguns dels seus membres podien restar seriosament perjudicats 5 .

\section{Els inicis dels preparatius de l'expulsió i la divisió de l'Estament Militar}

Els fets estudiats s'inicien quan es va decidir començar els preparatius per a portar a terme l'expulsió dels moriscos valencians. Amb la consulta del Consell d'Estat de 4 d'abril de 1609 es posà fi a la disputa existent entorn a la conveniència o no de fer-los fora i es va prendre la decisió definitiva. Des d'aquell moment es començà a debatre sobre com s'havia d'executar i, finalment, es va decidir iniciar la expulsió pel Regne de València ${ }^{6}$. Les preparacions es dilataren alguns mesos fins que el 30 de juliol es van emetre les primeres instruccions, una d'elles dirigida al marqués de Caracena, virrei de València. El secret era fonamental per a mantenir la pau necessària per a portar a terme l'expulsió. Tant és així que el dia 27 d'agost el virrei es congratulava de que els motius de l'operació encara restaven ocults, doncs encara que era patent que s'estaven realitzant preparatius per a iniciar alguna acció militar no s'havien

a les reunions tots els nobles i cavallers del regne, en la practica només acudien els que residien a la ciutat de València. MATEU I SANZ, 1677: 125-127.

5. L'expulsió dels moriscos és un tema que ha despertat l'interès dels historiadors des de fa temps i que com a resultat ha donat nombroses publicacions, sobre tot l'any 2009 per motiu del IV centenari de l'expulsió. Així doncs, ens ha sorprès que el tema que ací es tracta no hagués estat estudiat amb anterioritat. Doncs llevat d'algunes mencions de Tulio Halperin Donghi, Emilia Salvador y Manuel Lomas, cap autor contemporani ha abordat la posició de l'Estament Militar davant l'expulsió. HALPERIN DONGHI, 2008: 174, SALVADOR ESTEBAN, 24 (1998): 130-132 i LOMAS CORTÉs, 62/63 (2009): 128-131.

6. No s'analitza en aquest treball ni el problema morisc ni la logística de l'expulsió. Tanmateix cal senyalar que l'organització d'un procediment de tal magnitud va posar a prova la administració política i també militar de la Monarquia de Felip III. Tant per la quantitat de cristians nous que s'havien d'expulsar com per la seua situació geogràfica, s'hagué de dissenyar molt bé quina era la tàctica per a portar a terme una missió de tal envergadura. La dimensió demogràfica i espacial ja va ser senyalada fa ara 60 anys per Henry Lapeyre. No obstant no ha sigut fins a fa ben poc quan de la mà de Manuel Lomas s'ha contat amb un obra que tractés de forma global les dificultats administratives i logístiques que necessàriament anava a comportar l'expulsió. LAPEYRE, 1986. LOMAS CORTÉS, 2011. 
relacionat amb l'expulsió. No obstant, els rumors anaren en augment durant els primers dies de setembre fins al punt que alguns moriscos fugiren a les muntanyes ${ }^{7}$.

Des de finals d'agost els Estaments començaren a sospitar de les gestions que s'estaven portant a terme, ja que el marqués de Caracena el dia 24 informà a Felip III de una possible ambaixada que creia encaminada a esbrinar la finalitat dels preparatius que s'estaven portant a terme. En aquest sentit la resposta del rei va ser que no es donessin raons per a sospitar i en conseqüència no s'impedís l'execució de la missatgeria ${ }^{8}$. Resulta evident que els preparatius estaven despertant la curiositat de les elits del regne, encara que pareix ser que no tenien clara la finalitat a la que anaven encaminats. Damián Fonseca referia que els nobles intentaven contínuament esbrinar que s'estava obrant:

Visitavan más a menudo los titulados y otros barones a su excelencia y al patriarca y las damas a la virreyna, atravesando siempre esta conversación para ver si les podían sacar alguna palabra de donde fuessen conjeturando el intento de su magestad 9 .

Per això, després que arribaren les galeres per a l'embarcament, no ha de resultar estrany que el 5 de setembre l'Estament Militar designés tres nobles i tres cavallers per acudir en ambaixada al virrei. El motiu d'aquesta acció era demanar al marqués de Caracena que expliqués a quina finalitat estaven encaminats els preparatius i, també, expressar el desconsol que tenia l'Estament de que no es confiés en la noblesa per a portar a terme aquestes gestions ${ }^{10}$. Ja en

7. LOMAS CORTÉS, 2011: 55-65.

8. Ibidem: 68 .

9. FONSECA, 1612: 198

10. Encara que pot parèixer estrany al Regne de València i també en la resta de la Corona d'Aragó la paraula ambaixada tenia un sentit prou ampli doncs designava a totes aquelles comunicacions d'un alt nivell institucional que tenien una complexitat protocol-lària. És a dir, les relacions entre les institucions regnícoles i les representatives del rei es portaven a terme mitjançant ambaixada, normalment dels estaments, diputació, ciutat al virrei. Açò podria ser lògic en tant que el virrei com Alter Nos usava, per delegació, d'algunes preeminències del rei. No obstant les relacions entre les pròpies institucions regnícoles també s'anomenaven ambaixades, és a dir que quan un Estament es comunicava amb altre o amb la ciutat, o fins i tot alguns nobles importants també s'utilitzava el terme ambaixada.

Sobre l'ambaixada de 5 de setembre de 1609 Escolano refereix que foren designats don Jusep de Proxita i Borja, marqués de Navarrés i comte d'Almenara, don Lluís Castellar 
aquell moment la notícia de l'expulsió s'havia difós àmpliament per Madrid, la qual cosa pot fer-nos pensar que aquesta representació anava encaminada a confirmar si els rumors eren certs ${ }^{11}$.

Gaspar Escolano va fer una narració d'aquesta ambaixada que complementa el silenci de les actes estamentals al respecte ${ }^{12}$. Segons aquest cronista, quan els ambaixadors es presentaren davant el marqués de Caracena fou don Lluís de Castellar el que va exercir de portaveu. En la seua locució va iniciar recordant les innumerables ocasions en que l'Estament Militar havia servit als seus reis i senyors «con sus haciendas y vidas» i que per això els havien recompensat amb nombroses mercès. No obstant, referia que havien sigut enviats per l'Estament Militar a representar «el bivo desconsuelo con que quedan de verse no solamente no llamados ni empleados, pero aún effectivamente excluydos», doncs havien ofert la seua col-laboració en la empresa que s'estava iniciant i el virrei els digué que «no es menester». A la qual cosa Carcacena va respondre que precisament era la fidelitat de l'Estament la que permetia el secret de les operacions, ja que tant ell com sa majestat sabien que «los havian de hallar promptos a todos puntos para su real servicio, pero que aún no era hora» ${ }^{13}$. De manera que la resposta del virrei mantenia els dubtes de l'Estament, ja que ni confirmava les sospites ni tampoc les negava. Segons Manuel Lomas el virrei tenia una noció clara de la situació a la que s'enfrontava. Doncs, en la seua opinió, una confirmació haguera provocat la unitat dels nobles front la imminent expulsió. Per tant, el lloctinent va optar per mantindre la incertesa i

de Vilanova, comte de Castellar, don Francisco Llançol de Romaní, senyor de Gilet, Fabià Eslava Cucalón de Montull, Escipió Roca i Maximilià Cerdà. EsCOLANO, 1611, col. 1853.

11. LOMAS CORTÉS, 62/63 (2009): 130.

12. Aquest silenci de les actes no es estrany, doncs normalment només es recollia la decisió final que s'havia pres en la reunió. Així que moltes vegades, per a saber el que realment ocorria en les Juntes Estamentals, hem de recórrer a fonts complementaries com són els dietaris, la correspondència privada o els informes que els virreis enviaven amb certa regularitat per a informar al Consell d'Aragó i a sa majestat de l'activitat de les Juntes d'Estaments.

13. A més, segons Escolano el virrei es va oferir a escriure a sa majestat en creença de l'ambaixador enviat a la cort. EsCOLANO, 1611: cols. 1853-1856. Segons Fonseca el comte de Castellar va insistir al virrei que va respondre que no sabia res. FONSECA, 1612: 205-206. 
la divisió dins de l'Estament Militar ${ }^{14}$. En conseqüència, els dies 5 i 9 de setembre el Braç Militar es tornà a reunir sense prendre cap tipus de resolución ${ }^{15}$.

En la seua narració, Fonseca dona més informació del que va succeir dins de l'Estament. Dies després d'acudir al virrei i no obtenir resposta, el 14 de setembre la decisió d'enviar un ambaixador directament a sa majestat va quedar frustrada pel nemine discrepante. Encara que és sobradament conegut, convé recordar que les decisions de l'Estament Militar s'havien de prendre per unanimitat. De forma que el dia 14 no es prengué cap decisió, encara que tots van votar a favor llevat del senyor d'Andilla i el seu germà, «juzgando que no serviría la jornada sino de hazer gastos al reyno». Aquesta opinió no va ser ben vista «y estuvo muy cerca de aver aquel día un gran ruido en la Deputación» ${ }^{16}$, ja que acusaren als discrepants de no veure's afectats per no ser senyors de llocs de moriscos ${ }^{17}$.

Donat que no fou possible prendre resolució, els militars es tornaren a reunir el 16 de setembre. Com l'ambient encara estava alterat, el marqués de Caracena envià a Vicent San Juan de Aguirre $^{18}$, regent de la Reial Cancelleria, per a que advertís de que «tratassen sus negocios con razones, prudente y christianamente, sin alborotos ni amenazas». Però prompte les desavinences tornaren a fer-se patents, doncs encara que ja no es prestava una oposició frontal a fer ambaixada, ara la disputa estava en la manera de finançar-la. Mentre que uns defensaven que s'havia de fer a costa dels interessats, altres creien que s'havia de pagar de pecúnies de l'Estament ${ }^{19}$.

14. LOMAS CORTÉS, 62/63 (2009): 130.

15. Arxiu del Regne de València (ARV), Real Cancelleria, 527, ff. 387-388. Emprem el terme Braç com a sinònim d'Estament, per tal d'evitar repeticions. Som conscients de les diferències que refereix Mateu i Sanz entre Braç i Estament, però també cal senyalar que a la documentació s'usen ambdós termes indistintament.

16. Les Juntes de l'Estament Militar es solien celebrar en la Casa de la Diputació, actual Palau de la Generalitat.

17. FONSECA, 1612: 206.

18. Vicent San Juan de Aguirre va ser regent de la Cancelleria des de 1604 fins a la seua mort el 16 de setembre de 1609. CANET APARISI, 1990: 57.

19. Convé assenyalar en aquest punt que per a que l'ambaixada fos finançada per les arques de la Generalitat calia que fora enviada per motiu de Contrafur o Cas Inopinat i nomenar ambaixador en reunió conjunta de elets dels tres Estaments i oficials i diputats de la casa de la Diputació. En aquells casos en que s'enviava ambaixada per un sol Estament era aquest el que havia de córrer amb les despeses. Una situació similar a la 
En este punto estuvieron altercando por un gran rato y cansados ya de dar bozes, viendo que no salían con su yntento, persuadidos que en aquella embaxada consistía alguna parte de su remedio, por lo menos que no quedarían con aquella manzilla en el coraçón, echaron mano a las espadas y se començaron a sacudir con tanta colera y ceguera que fue maravilla no salir muchos heridos y muertos.

Per a calmar els ànims el virrei va enviar a don Juan de Castellví, però, després d'un breu temps de tranquil.litat, l'Estament es va tornar a alterar ${ }^{20}$. En aquesta ocasió la gent del carrer "entendiendo que se matavan» va avisar al regent San Juan de Aguirre que va acudir per a intentar posar pau, però «fue tanto su sobresalto» que per la seua avançada edat i dèbil salut «le dio un paroxismo» i va morir ${ }^{21}$.

La mort del regent no ajudà a calmar la situació, doncs es començaren a estendre rumors de que l'havien matat. En conseqüència el virrei manà empresonar alguns nobles, però no es pogué provar la implicació de ningun cavaller en la defunció d'Aguirre. De forma que, tenint en compte l'edat del regent, es va creure que era probable que «la passión y alboroto lo acabessen».

Després de totes aquestes calamitats l'Estament es tornà a reunir aquella mateixa vesprada, i en aquesta ocasió aquells que s'havien oposat a l'ambaixada van decidir no acudir a la reunió per tal de no empitjorar la situació $^{22}$. Així que en la vesprada del 16 de setembre es va decidir que «se faça embaixada o missatgeria a sa magestat el rey nostre senyor» i que «per a la execució de dita embaixada se hagen de nomenar y nomenen en la forma y manera que aprés se delliberarà dos embaixadors o missatgers, hu dels quals

d'aquesta ambaixada es va donar a 1654 quan també l'Estament Militar va enviar un altra ambaixada en solitari. GUIA MARíN, 51-52 (2001-2002): 315-335. La legislació sobre el finançament de les ambaixades del Regne de València que en aquell moment estava en vigor eren el fur 94 de 1564 i els 58 i 138 de 1585. SALVADOR ESTEBAN, 1972: 34-35, 96-97 i 114. Cal dir, també, que no només a València el finançament de l'ambaixada va suposar problemes, doncs en l'ambaixada que la Diputació d'Aragó va deliberar també es van tenir dificultats en aquest sentit, doncs el governador intentà impedir que la cort del Justícia accedís a pagar els les despeses per tal d'evitar la tramitació de l'ambaixada. LOMAS CORTÉS, 2008: 86-88.

20. FONSECA, 1612: 207-208..

21. ESCOLANO, 1611: cols. 1857-1858.

22. FONSECA, 1612: 209.

Revista de Historia Moderna, n. ${ }^{\circ} 36$ (2018) (pp. 84-113) | ISSN-e: 1989-9823 | ISSN: 0212-5862 
senyor de vassalls y lo altre que no tinga vassalls alguns» ${ }^{23}$. Que s'enviaren dos ambaixadors no era estrany donada la importància de l'assumpte. També es va decidir nomenar un representant que fos baró i altre que no, per tant, dos sectors als que l'expulsió afectaria de forma molt diversa. Açò resulta destacable si tenim en compte que entre els arguments que s'havien emprat contra els opositors a l'ambaixada destacava el de que no eren senyors de llocs de moriscos.

Una vegada vençuda la divisió interna de la noblesa valenciana sobre la conveniència de realitzar una ambaixada al rei, s'iniciaren els preparatius per a portar-la a terme. El dia 17 de setembre de 1609 el síndic de l'Estament, que en aquell moment era Pere Gastans de Soler, va seleccionar dotze elets, sis nobles i sis cavallers, per a que foren els encarregats de l'elecció dels emissaris i de la redacció de les instruccions i memorial. Aquell mateix dia es designaren com ambaixadors a don Felip Boïl de l'Escala, senyor de Manises, i a don Joan

23. Archivo del Reino de Valencia (ARV), Real Cancillería, 527, ff. 388-397. Com senyala Manuel Lomas el marqués de Caracena va informar de que s'havia decidit fer ambaixada amb carta de 17 de setembre de 1609. LOMAS CORTÉS, 2011: 68.

No era estrany que es feren ambaixades al rei doncs era un dret que els vassalls pogueren acudir al seu senyor per a referir les seues queixes i buscar remei. Les ambaixades estaven en aquest moment bastant regulades pels furs. Però aquestes lleis només parlaven de les ambaixades del tres estaments en nom del regne, i altres de les de les ciutats. No hem trobat legislació relativa a ambaixades dels Estaments per separat, però, com hem vist en aquest cas, es realitzaven amb normalitat. Sobre açò cal no oblidar que el costum era considerat llei i per tant, si les ambaixades del Militar es produien amb normalitat els braços no tenien la necessitat de demanar al rei que reconegués aquest dret mitjançant un fur o un acte de Cort.

Com a exemple de que les ambaixades eren una cosa acostumada es poden senyalar els treballs de José Antonio Martínez, Emilia Salvador, Carmen Pérez, Rafael Benítez Lluís Guia o jo mateix.

Cal destacar, com a obra de referència per al tema la de David Bernabé sobre les ambaixades de la ciutat d'Oriola. De l'obra d'aquest autor es pot observar una diferència destacable del sistema usat per aquesta ciutat a l'usat pels Estaments, doncs Oriola contava amb un síndic permanent a la cort encarregat dels assumptes ordinaris. Caldrien més estudis sobre els municipis valencians per a saber si bé aquest sistema era comú a totes elles o bé era una particularitat. MARTíNEZ BARA, 1973, II: 197-214. SAlVAdOR EstebAn, 1995, 3: 347-365. PÉREZ APARICIO, 13-1 (1993): 327-340. BeníteZ SÁNCHEZ-BlANCO, 60-61 (2010-2011): 303-325. GUIA MARÍN, 51-52 (2001-2002): 315-335; 42(1992): 33-45. FUERTES BROSETA, 42 (2016): 249-264. BERNABÉ GIL, 2007; 2008: 429-444. 
Vallterra i Blanes. No fou fins al dia següent, 18 de setembre, quan es van llegir les instruccions que els enviats a la cort havien d'acomplir ${ }^{24}$.

La «Instructió dels elets del estrenu Bras Militar de la ciutat y regne de València» estava composta de sis capítols: 1 . En primer lloc, s'encarregava als ambaixadors que partiren immediatament de la ciutat de València per anar allà on estigués el rei per a explicar-li «ab paraules breus i substancials la causa de la sua tramesa» que era «significar y que lo dit Estament Militar y tots los singulars de aquell estan molt disposts y promptes per servir a sa magestat ab ses persones haziendes y vides en la present y altra qualsevol occasió», però com la intenció de sa majestat era la d'expulsar als cristians nous del regne «no se ha pogut escusar lo dit estament de significar a sa magestat los irreparables danys, desdijes, aflections y calamitats que forçosament se haurien de seguir al dit regne de la execució de semblant intent». I per això els manaven entregar el memorial per a suplicar al rei que fora servit «suspendre y revocar la dita resolució». 2. En el segon capítol, es manà que, una vegada entregat el memorial al rei es procurés obtenir audiència amb la reina per a que «en ocasió tan apretada no li falte la clemència, protecció y amparo». 3. En tercer lloc, s'encarregà als ambaixadors que es reuniren amb el duc de Lerma per a buscar el seu favor. 4. Així mateix, en el quart punt, s'encomanà reunir-se amb altres personatges d'especial importància en la política de la cort com eren: el duc del Infantado, el conestable de Castella, el duc de Cea, els confessors dels rei i de la reina i el vicecanceller del Consell d'Aragó. 5. En cinquena posició, s'escrigué que si el rei o els seus ministres proposaven algun tipus de tracte que procuraren per tots els medis aconseguir temps per a que els Estaments pogueren deliberar. 6. En sisè lloc, es digué als ambaixadors que informaren amb tanta freqüència com fos possible sobre l'estat dels negocis, i que de cap manera se'n tornessin a València sense ordre exprés de l'Estament Militar. Per acabar, deixaven la resta de coses «a la molta intel-ligència y prudència dels dits ambaixadors $»^{25}$. Juntament amb aquestes instruccions es va entregar als

24. ARV, Real Cancillería, 527, ff. 398-399.

25. ARV, Real Cancillería, 527, f. 400r-401v. Aquestes instruccions són molt similars a altres del mateix període. Fins i tot si acudim al que senyala David Bernabé sobre les que s'entregaven als ambaixadors de la ciutat d'Oriola, són molt similars. Doncs com refereix aquest autor quasi totes elles incloien, a més d'una breu explicació dels assumptes a tractar, la relació de les persones amb les que havien de reunir-se i també 
emissaris el memorial que havien d'entregar, compost de 13 capítols, i també les cartes de creença que s'havien de lliurar a les reunions amb sa majestat i altres personatges ${ }^{26}$.

Després de rebre aquestes instruccions els ambaixadors partiren cap a Madrid. La decisió d'enviar-los no havia estat fàcil, en un primer moment pels dubtes sobre a què estaven encaminats els preparatius que des de feia temps s'estaven produint i que el virrei no va poder ocultar donada la seua magnitud. I després s'hagué de vèncer la pròpia divisió interna del Braç Militar, que com hem vist no va estar exempta de violència. No obstant això, va imposar-se la opinió d'aquells que desitjaven acudir a sa majestat per a suplicar-li que no continués amb la decisió d'expulsar els moriscos del regne. En aquest sentit, resulta destacable que uns mesos després, entre novembre i desembre de 1609, una vegada ja iniciat l'embarcament a València, la Diputació del Regne de Aragó fera ús del mateix recurs per a demanar al rei que no fera el mateix amb els moriscos d'aquell territori. Les similituds no acaben ací, doncs els diputats aragonesos també optaren per fer una ambaixada dual, enviant dos representants. En aquesta ocasió s'envià a un diputat noble, el duc de Villahermosa, i l'altre, el doctor Martín Carrillo, era eclesiàstic, que com assenyala Manuel Lomas representaven a dos sectors amb opinió diversa dins de la Diputació aragonesa. Mentre que la posició oficial de l'organisme era l'oposició, els dos diputats eclesiàstics eren favorables a l'expulsió ${ }^{27}$. Per

algunes advertències sobre com s'havien de fer els negocis. En definitiva, com senyala el professor Bernabé la seua funció era, «a un tiempo, formativa e informativa, pues se trataba con elles de instruir al mensajero en los negocios que debía gestionar en la corte, no solamente recordándole las materias a tratar, sinó facilitándole los argumentos que debía utilitzar en las entrevistes y diligencias a realizar, orientándole en las actuacions a desarrollar e incluso previniéndoles ante posibles contratiempos». BERNABÉ GIL, 2007: 231-234.

26. ARV, Real Cancillería, 527, f. 407v-408v. David Bernabé refereix sobre Oriola on, amb el nom de sindicat, s'entregava un document amb els poders i causa per les que havia estat enviat l'ambaixador per a que no quedés dubte de que contava amb recolzament institucional. En les ambaixades dels estaments era la carta de creença al rei la que feia aquesta funció, doncs s'emetia amb el segell dels estaments, en aquest cas el del Militar. Així mateix també convé senyalar que les personalitats a les que s'escriviren cartes de creença coincideixen amb aquells personatges als que solia escriure la ciutat d'Oriola quan enviava un síndic a la cort. BERNABÉ GIL, 2007: 228-230, 234.

27. LOMAS CORTÉS, 2008: 81-99. 
la seua banda, l'Estament Militar de València va decidir enviar un representat senyor de llocs de moriscos i altre que no ho fos. De manera que tant l'Estament Militar de València com la Diputació d'Aragó van optar per la mateixa estratègia d'enviar dos representants amb interessos diversos per portar a terme les seues ambaixades. La qual cosa no ha de sorprendre'ns si ho posem en relació amb el que Antonio Álvarez-Ossorio assenyala sobre aquest tipus d'ambaixades duals, ja que, en la seua opinió, enviar a dos persones amb interessos distints era una garantia per a que es seguiren estrictament les instruccions doncs un ambaixador vigilaria l'acció de l'altre ${ }^{28}$.

\section{El canvi de posició de l'Estament i l'execució de l'ambaixada}

Una vegada els ambaixadors ja havien iniciat el seu viatge, en reunió de l'Estament Militar de 22 de setembre es va llegir una carta de Felip III d'11 de setembre en la que argumentava la seua decisió d'expulsar als moris$\cos ^{29}$. Sa majestat comunicava les raons que s'havien tingut en compte per a decidir fer-los fora, que són les que s'havien exposat en les consultes del Consell d'Estat de 30 de gener de 1608 i 4 d'abril de 1609 i que més tard es repetirien en la crida de l'expulsió ${ }^{30}$. Com a primer argument es donava el fracàs dels intents d'instruir-los com a bons cristians, "pues no se ha visto que ninguno se haya convertido sino antes crescido de día en día su obstinación y el desseo y voluntat que siempre han tenido de machinar contra essos reynos». Així doncs, el monarca exposava que des de feia anys homes molt doctes li havien donat el consell de «castigarlos en sus vidas y haziendas, porque la notoriedad de sus delictos y la gravedad y atrocidad dellos los tenia convencidos de hereges, apostatas y proditores de lesa magestad divina y humana». Encara així s'havia intentat evitar el càstig executant altres mesures alternatives, no obstant, s'havien tingut notícies molt certes de que els moriscos havien enviat a Constantí Pla al Marroc per a negociar amb els turcs i amb Mulei Cidàn

28. Álvarez-OSSORIO AlVARIÑo, 6 (2000): 278-283.

29. Aquest mateix dia 22 de setembre de 1609 es publicà el bàndol d'expulsió dels moriscs. LOMAS CORTÉS, 2011: 87.

30. Ibidem: 42-46. El dia 22 de setembre es va fer crida publica en la que es feia saber la decisió d'expulsar els moriscos. En ella s'incloïen, a més dels arguments que justificaven la decisió, els capítols que regulaven el procediment. MARTínEZ, 1997: 568-570. 
per a demanar la invasió de la península «assegurándoles que hallarán ciento y cinqüenta mil hombres tan moros como los de berbería que les assistirían con sus vidas y haziendas». Aquesta última raó, la d'un suposat perill d'invasió que suposava una aliança entre els cristians nous i els berbers, va resultar la principal justificació de l'expulsió.

Per tant, s'emprà la raó d'estat per tal de portar a terme una mesura tan dràstica com l'expulsió per a evitar un mal encara major com podia ser una eventual invasió des de Barbaria. Cal assenyalar que no hi ha proves que puguen fer pensar que aquest perill fora real, sinó més bé es va emprar per tal d'oferir un argument amb força suficient per a vèncer les discordances que una mesura com l'expulsió dels nous convertits anava a despertar. Per tant, exposant un fals perill immediat s'aconseguia justificar plenament la decisió final $^{31}$. En conseqüència, al final de la seua carta dirigida a l'Estament Militar, Felip III expressà que actuava «desseando complir con la obligación que tengo de procurar la conservación y seguridad de mis reynos y en particular la de esse $y$ de los buenos y fieles subditos dél por ser más imminente su peligro». És a dir que segons la Corona s'actuava seguint la màxima de la salus populi suprema lex, i garantir la seguretat de la monarquia i els seus súbdits era la prioritat que havia desencadenat el procés per a fer fora als moriscos.

Per totes les raons ja assenyalades i la major gloria de Déu, el monarca escrivia la seua decisió: "he resuelto que se saque de esse reyno y de los de Castilla todos los moriscos que hay en ellos». Així mateix esperava que, donades unes causes «tan urgentes y precissas», l'Estament Militar col-laborés «pues la necesidad no da lugar que se dilate para que nuestros enemigos no nos prevengan». Així que, finalment, ordenà a l'Estament que actués segons les instruccions del virrei, marqués de Caracena.

Després d'haver llegit els arguments de sa majestat en sessió del Braç Militar a la reunió de 22 de setembre els allí reunits

estimaren lo que era rahó, la mercè tan senyalada que lo rey nostre senyor és estat servit fer al dit regne en prevenir y evitar los danys, desdiches y

31. Com assenyala el professor Rafael Benítez va ser aquesta raó d'estat la que va acabar per justificar l'expulsió, doncs davant el perill de la invasió des del nord d'Àfrica i la sospita de col-laboració morisca, la mesura de fer fora als cristians nous era un mal menor. Aquest discurs va ser la principal justificació, encara que és dubtable que tal invasió i els contactes amb els moriscos foren certs. BENíTEZ SÁNCHEZ-BLANCO, 2012: 143-205. 
treballs que se aparellaven y lo effecte dels tractes secrets, proditió de dits moriscos, que contra aquell se machina. E induint de les coses dessus dites precissa obligació de ajustar-se ab la punctualitat y obediència acostumades a la voluntat del rey nostre senyor.

Per tant, designaren sis elets, tres nobles i tres cavallers, per a acudir en ambaixada al marqués de Caracena per a comunicar-li que els membres de l'Estament «estaràn molt disposts y aparellats per a servir a sa majestat y ajudar ab persones, vides y haziendes a la deguda y punctual execució de la real voluntat y resolució presa en açò per sa magestat». A la qual cosa el lloctinent va respondre amb agraïment, de manera que es nomenaren quatre elets, dos nobles i dos cavallers, per a ajudar al virrei en la tasca ordenada pel rei i també informar a l'Estament d'allò que s'anava fent ${ }^{32}$. Aquell mateix dia es va deliberar respondre la carta del rei de dia 11 exposant a sa majestat que l'Estament anava a col-laborar amb la fidelitat acostumada i també per agrair la mercè que s'havia fet.

De manera que l'Estament Militar, que després d'un debat violent s'havia posicionat en contra de l'expulsió enviant dos ambaixadors a sa majestat per tal d'evitar que es produís, quan va llegir les raons i va veure que la decisió era ja definitiva no va dubtar en canviar de posició i col-laborar en la gran empresa que s'estava iniciant ${ }^{33}$. En opinió d'Escolano açò va ser provocat per la divina providència, doncs l'enfrontament dins de la noblesa va retardar l'ambaixada el temps suficient per a que la protesta fos inútil.

Como los decretos del cielo son incontrastables no havía cosa en el reyno que de sí pudiesse servir de estorvo para la expulsión de los moriscos que no se convirtiesse en medio para efetuarla. Y ansí puso Dios en el Estamento de los militares, que son el nervio deste reyno, tanta división que no acabando de concertarse en lo

32. Foren nomenats quatre elets per a que «assistixquen al il-lustríssim y excel-lentíssim senyor marqués de Caracena lloctinent i capità general per sa magestat en la dita ciutat y regne per a que puguen anar entenent y sabent de sa excellència lo que se anirà fent e innovant en dit negoci y donarne noticia al dit estament a fi que essent puga emplear totes les ocasions que se offeriran de servir a sa magestat». ARV, Real Cancillería, 527, f. 412-413.

33. Com una possible causa del canvi de posició dels nobles cal pensar en que esperaven ser recompensats amb mercès i recompenses. Així mateix, com assenyala Casey la Corona ja havia fet la tasca de guanyar-se el favor d'alguns nobles i senyors concedintlos hàbits. CASEY, 2009: 143-148. 
de la embaxada dieron con las largas lugar a que se executassen las órdenes del rey, y que se les passasse la sazón de negociar» ${ }^{34}$.

Mentre a València els militars ja s'havien ofert a ajudar al virrei en l'expulsió, a Madrid els ambaixadors portaven a terme la tasca que els havien encomanat, ignorant que la posició de l'Estament havia canviat. De forma que els enviats van obtenir audiència amb sa majestat i li van representar que fer fora als moriscos seria «la universal ruyna deste reyno», també van indicar que amb aquella decisió es transgredien «quatro o cinco fueros jurados por su mages$t a d{ }^{35}$. En conseqüència el rei va respondre que ja havia tingut en compte els inconvenients que havien sigut consultats amb homes doctes i que, encara que eren importants les raons que referien, «contrapesavan más las que havían movido su real pecho a hazerla y que a aquella hora era cierto estava ya publicada y executada en Valencia» ${ }^{36}$.

Després d'haver sentit la resposta del rei, els ambaixadors entregaren el memorial que havien redactat els elets de l'Estament Militar. El document que entregaren a sa majestat estava compost de 13 capítols en els que s'exposaven «los irreparables danys, desdiches, affictions y calamitats que forçoçament se han de seguir de la execució de semblant intent y resolució» esperant amb açò que el rei «reste plenament informat dels dits danys per a que per sa innata clemència se incline a apiadar-se del dit regne manant suspendre y revocar la dita resolució».

En primer lloc, entre els capítols 1 i 9, s'exposaven els danys econòmics que es seguirien de l'expulsió. Doncs s'assenyalava que cada any els cristians nous pagaven entre 9 i 10 milions de lliures de renda. Aquests diners eren el principal suport de l'Església del regne, la qual cosa incloïa la catedral, parròquies, monestirs, convents i hospitals que restarien totalment arruïnats

34. Per la seua banda Damià Fonseca era d'altra opinió, doncs opinava que si la carta del rei hagués arribat abans s'hagueren evitat les dissensions i conflictes dins de l'Estament Militar. ESCOLANO, 1611: col. 1859. FONSECA, 1612: 210.

35. Com ja hem referit, la raó d'estat va acabar per justificar l'expulsió de manera que aquesta s'anteposava al compliment de les lleis. Com assenyala Rafael Benítez «ilustres juristas y moralistas daban por bueno que el bando de expulsión hubiera marginado 'las reglas ordinarias de derecho', basándose en la razón de estado, pero -debe subrayarse-no de forma arbitraria sino atendiendo al servicio de Dios y al bien general de los reinos de España». BENÍTEZ SÁNCHEZ-BLANCO, 2008: 226.

36. ESCOLANO, 1611: col. 1860-1861. 
després de l'expulsió. La mancança d'aquests ingressos es deixaria sentir per tota la població del regne, ja que també resultaria en dany de nombrosos nobles, cavallers i ciutadans ${ }^{37}$. Així mateix, l'Estament informava que el regne corria el risc de quedar desbastit de tots els productes en els que la mà d'obra morisca era part fonamental de la producció. També el despoblament d'algunes zones seria terrible tant per la pèrdua de rendes, com perquè cessaria el comerç i les rectories quedarien arruïnades. Així mateix argumentaven, que tot l'arquebisbat de València es veuria afectat i en risc de quedar en estat ruïnós, tant per la disminució de rendes com per l'absència de feligresos.

Tanmateix el capítol més important, el 10, era el dedicat als danys que rebrien tots els ducs, marquesos, comtes i demés senyors de vassalls que des dels temps de la conquesta havien rebut la mercè dels reis de poder conservar aquests cristians nous sota la seua jurisdicció i per això «estan molt confiats y certs que vostra magestat per sa real clemència se servirà no donar lloch a la dita extracció dels nou convertits». Perquè aquests nobles restarien «del tot arruinats y destruits, sens poder-se sustentar ni viure y impossibilitats de poder casar y acomodar a sos fills y filles y ab contingència, y casi certesa, de haver de perir de fam».

En el capítol 11 s'emfatitzava la importància de mantenir als moriscos dins del regne, la qual cosa quedava demostrada per els nombrosos furs que els reis havien atorgat protegint als cristians nous i prohibint que sortiren del territori valencià. A més a més, com es referia en el capítol 12, la fidelitat

37. Sobre estos primers capítols del memorial ja va tractar Emilia Salvador per tal d'abordar el tema dels censals, doncs resulta un testimoni de que prèviament a l'expulsió ja es tenia consciència de que els senyors de moriscos no podrien fer front als censals desprès de l'expulsió, la qual cosa quedà plasmada en una pragmàtica de 1614 que fixà els interessos en un $5 \%$, provocant la reacció dels censalistes que argumentaren que no era just rebaixar els interessos de tots els censals quan només uns pocs senyors havien sigut afectats. SALVADOR ESTEBAN, 24 (1998): 127-146. He de assenyalar sobre aquest assumpte que les conseqüències es deixarien sentir encara després del que refereix la professora Salvador, doncs els tres Estaments enviaren dos vegades a la Cort, en 1625 i 1626, com ambaixador a don Francisco Roca i Borja. En la segona ocasió es demanava al rei que fera una comissió especial al regent Francisco de Castellví per a que esbrinés quines eren les forces del barons del regne per a que feren front als censals en la mesura de les seues possibilitats, doncs els convents, monestirs, pobres i altres obres pies necessitaven d'aquests ingressos i sense ells estaven passant per grans penúries. ARV, Real Cancillería, 531, ff. 188 i ss. 
dels moriscos havia sigut indubtable, ja que fins i tot durant la Germania havien donat suport a l'emperador Carles V. Per a finalitzar, en l'últim capítol es defensava que, per la suma de tots els arguments abans referits i els danys que desencadenaria, la conservació del dit regne passava per mantenir els cristians nous dins del regne ${ }^{38}$.

Després d'haver rebut l'ambaixada del senyor de Manises i don Joan Vallterra i haver llegit el memorial, Felip III va respondre a l'Estament Militar amb carta de 27 de setembre. En ella el monarca referia que havia sentit als ambaixadors «con mucho sentimiento de no poder condescender a vuestra demanda por las causas que les mandé escrivir». El rei suposava que d'haver arribat abans la seua argumentació s'haguera evitat l'ambaixada doncs en la seua opinió hi havia «tantos y tan ciertos avisos de sedición y crimen de lesa magestad divina y humana como essa gente machinava y del eminente peligro que corriades todos de perder vuestras vidas y haziendas» ${ }^{39}$.

Així doncs, la tàctica de l'Estament Militar era referir els notables danys que es seguirien de l'expulsió dels moriscos del regne per tal de que el rei es replantegés la situació i fes marxa enrere en la decisió de fer-los fora. Per contra, en l'ambaixada que alguns mesos després portaren a terme el duc de Villahermosa i Martín Carrillo en nom de la Diputació aragonesa l'estratègia va ser prou diferent, doncs encara que l'objectiu era el mateix, van optar per un discurs molt distint. En lloc de referir els danys van destacar les diferències amb la situació dels moriscos valencians. Doncs l'argument principal que havia justificat la mesura a València havia sigut el suposat perill de que els cristians nous col-laboraren en una invasió dels barbarescos, la qual cosa no podia succeir en el Regne d'Aragó per estar allunyat de la mar. A més, destacaven que a Aragó els moriscos eren menys nombrosos i havien estat més receptius a la evangelització que els valencians. Encara així proposaven la mesura de llevar a tots els moriscos aragonesos els xiquets d'entre 3 i 8

38. El memorial en ARV, Real Cancillería, 527, ff. 402-407. Hem decidit incloure aquest memorial com apèndix documental, doncs encara que ací no ens centrem en fer un anàlisis extens d'ell, pot ser molt útil per a altres investigadors que vulguen estudiar l'expulsió dels moriscos i les seues conseqüències.

39. ARV, Real Cancillería, 527, f. 424. 
anys per a que foren educats per cristians vells, de manera que no tinguessin contacte ni record dels seus pares ${ }^{40}$.

Uns dies després d'haver suplicat que no s'executés l'expulsió, el senyor de Manises i Joan Vallterra foren els encarregats de mostrar al monarca la nova posició del Militar. En una nova audiència amb el rei van entregar la carta de 22 de setembre en la que es comunicava l'obediència de l'Estament i la seua disposició a col-laborar en la tasca d'expulsar als nou convertits. Així doncs, Felip III en carta de 29 de setembre corresponia a la predisposició de la noblesa i assenyalava que s'havia alegrat de «vuestras obras y palabras al amor y voluntad que siempre me prometí de vuestra singular y antigua fidelidad. $Y$ assí hos doy por ello muchas gracias, assegurandoos que procuraré con mucho desvelo el reparo del daño y descomodidad que de la expulsión de los moriscos se os siguiere a vosotros y a todo el reyno» ${ }^{41}$.

Un temps més tard, en la reunió de l'Estament Militar de 6 de octubre de 1609 , es van llegir i respondre les dos cartes de sa majestat, la de 27 que fou entregada pels ambaixadors i la de 29 de setembre que fou rebuda a través del marqués de Caracena. Així en la carta del Militar es deia que si s'hagueren comunicat abans els arguments que s'havien tingut en compte per a decidir la expulsió l'Estament haguera evitat trametre l'ambaixada. De manera que els nobles assenyalaven que es podia contar amb la seua fidelitat provada perquè molts d'ells «comencen ja a sentir y experimentar en sos patrimonis y haziendes los danys y treballs representats a vostra magestat per los dits embaixadors tots los quals passen ab molt gran consolació y gust per sa natural obediència y amor» ${ }^{42}$.

\section{Altres beneficis de la fidelitat}

A tenor del que acabem d'exposar podria parèixer que el Braç Militar, veient que la decisió del monarca era definitiva i atret per la promesa de mercès, va unir-se sense reserves al projecte de Felip III. No obstant, la documentació ens mostra que aquesta afirmació ha de ser matisada. És evident que mantenir una oposició frontal ja no tenia sentit una vegada estaven tan avançats

40. LOMAS CORTÉS, 2008: 88-89.

41. ARV, Real Cancillería, 527, ff. 424-425.

42. ARV, Real Cancillería, 527, f. 425. 
els preparatius i la crida pregonada, però pareix ser que la col-laboració tenia altres avantatges més enllà de les recompenses.

Quan el dia 22 de setembre es nomenaren quatre elets per a ajudar i estar junt al virrei durant l'organització, també tenien la funció de supervisar i informar a l'Estament de tot el que s'anava obrant. Com sabem, entre les funcions dels Estaments estava la de controlar i vetllar per l'observança de les lleis i en aquest sentit col-laborar en els preparatius suposava un gran avantatge, doncs des de dins es podia observar molt millor quines eren les actuacions de la Corona.

Com a mostra d'açò podem donar que l'l d'octubre de 1609 el Militar va deliberar fer ambaixada juntament amb els altres estaments per a recordar al marqués de Caracena que els allotjaments de tropes que segurament anava a implicar la logística de l'expulsió estaven prohibits pels furs i, per tant, els tres Estaments demanaven que s'evitaren ${ }^{43}$. No obstant, aquesta demanda no va sortir efecte, ja que el 4 de novembre es va protestar perquè s'havien allotjat companyies de soldats en Moncada i com els homes estaven absents i només restaven les dones a casa, els soldats s'aprofitaren de la situació i «usaren de termens indecents y descomposts y contra voluntat de aquelles los posaren y aloxaren en casa als dits soldats, lo que a més de mal terme y descompostura és contrari y repugnant als furs, privilegis, usos y bons costums del present regne». Per això, es va fer de nou ambaixada al virrei per a representar «lo sentiment ab que està lo dit Bras Militar per los dits excessos y supliquen axí lo dit justícia de Moncada com los demés culpats sien condignament punits y castigats $»^{44}$.

Aquesta acció de protesta es va repetir poc després, el 14 d'octubre, perquè s'estaven incomplint les promeses de compensació que s'havien fet als nobles. En la crida de l'expulsió es deia que els bens dels moriscos havien d'anar a parar als senyors dels llocs on vivien els cristians nous, però la Junta de Patrimoni volia incorporar a les arques reials els bens dels expulsats que vivien en terres de reialenc ${ }^{45}$, la qual cosa era d'esperar que provoqués la

43. ARV, Real Cancelleria, 527, ff. 422-423.

44. ARV, Real Cancelleria, 527, f. 430.

45. ARV, Real Cancelleria, 527, f. 427. 
reacció del Militar, ja que alguns dels seus membres es veien clarament perjudicats per aquesta decisió.

De manera que l'Estament Militar va aprofitar el seu canvi per a situar quatre dels seus membres en una posició pròxima al virrei. Aquesta decisió, si només la relacionem amb els fets anteriors, podem creure que anava encaminada solament a ajudar en l'organització logística i assessorar al lloctinent per tal d'obtindre mercès, però si veiem l'activitat posterior observem que aquests quatre elets permetien als Estaments estar convenientment informats del que s'anava obrant. Per tant, la col-laboració amb la corona va permetre als Estaments, i especialment al Militar, defendre els seus interessos i també vigilar que durant l'execució dels embarcaments no es transgrediren els furs.

\section{Unes reflexions finals}

Com hem vist, dins de l'Estament Militar des del moment en que es va difondre la notícia de la possible expulsió dels moriscos es va despertar l'oposició a aquesta mesura d'un sector important del mateix. Sembla lògic que els senyors de llocs de moriscos s'oposaren a la decisió, de fet alguns nobles també protestaren de forma individual. El mateix duc de Gandia, un dels més perjudicats per la mesura, va escriure personalment al marqués de Caracena assenyalant els danys que comportaria l'expulsió. No s'equivocava Carles de Borja al denunciar els perjudicis que seguirien a la seua hisenda doncs, com refereix Santiago La Parra, les conseqüències en el ducat de Gandia foren negatives, destacant la despoblació i l'endeutament ${ }^{46}$. No obstant, en opinió de Eugenio Ciscar, caldria relativitzar aquesta hipòtesis, doncs es donaren situacions diverses dins dels senyorius dels Borja, ja que en algunes zones no alcançaren un nivell demogràfic i de rendes similars fins molts anys després, mentre que en altres zones com les valls d'Ebo i Gallinera l'expulsió va permetre renegociar els arrendaments i els ingressos dels ducs augmentaren

46. El professor La Parra assenyala que una de les principals conseqüències de l'expulsió en el ducat de Gandia va ser la reducció del cultiu de la canyamel i la producció de sucre, doncs era una tasca portada a terme principalment per moriscos. Açò va provocar que els ingressos dels ducs de Gandia minvaren considerablement ja que obtenien gran part de les seues rendes de la canyamel. LA PARRA LÓPEZ, 16 (1990): 217-232. Sobre la acció del duc de Gandia en l'expulsió es pot consultar. LOMAS CORTÉS, 62/63 (2009): 132-141. 
en pocs anys ${ }^{47}$. Així mateix, algunes de les raons referides en el memorial entregat per l'Estament a Felip III, com la del descens de les rendes eclesiàstiques pareixen hui descartades a tenor dels estudis de Manuel Ardit ${ }^{48}$. Cal pensar que, encara que alguns historiadors defenen que els efectes no van ser tan dolents, en aquell moment era normal que una mesura tan important despertés una oposició i un temor en aquells senyors que la seua subsistència i rendes depenien en gran mesura dels seus vassalls moriscos.

A tenor d'açò, l'enfrontament dins de l'Estament Militar confirma que l'expulsió no anava a afectar a tots els seus membres de la mateixa manera. Tot i això va sortir vencedora l'opció de fer front a l'expulsió, i encara amb el nemine discrepante es va designar com ambaixadors al senyor de Manises i don Joan Vallterra. Tanmateix, la victòria no va ser completa doncs es va recórrer a una ambaixada dual per tal de que ambdós enviats es controlaren mútuament.

Així mateix, tampoc ha de resultar estrany que el Militar no tractés d'iniciar els procediments per a declarar la situació com a contrafur o com a cas inopinat i optés per enviar una ambaixada en solitari. Doncs les dificultats per a enviar l'ambaixada en representació del regne eren grans. Per a fer-ho i poder accedir al finançament de la Generalitat després de la decisió unànime del Militar calia que els altres dos estaments concordaren amb ell i nomenaren elets per a que es reuniren amb els oficials i diputats de la casa de la Diputació per a fer nominació de l'ambaixador. En conseqüència, la situació de setembre de 1609 hagués resultat molt difícil o, fins i tot, impossible portar a terme aquests procediments. En primer lloc, perquè haguera suposat una important dilació en l'execució de la missatgeria. I, en segon lloc, per la dificultat de que els altres dos estaments es sumaren a la decisió del Militar ${ }^{49}$.

47. CisCAR PAllarÉs, 24 (2006): 123-152. En una mateixa línia que Ciscar podem situar a Manuel Ardit qui també assenyala que els efectes econòmics de l'expulsió no van ser tan greus ni van suposar una reducció important de les rendes. Per altra banda, aquest autor indica que l'absència dels moriscos va possibilitar un canvi en el camp valencià deguda a les modificacions en el repartiment i el sistema de propietat. De manera que es va produir una simplificació reforçant el sistema de propietat i de cultiu dels cristians vells amb l'eliminació de l'usat pels moriscos, la qual cosa va facilitar la racionalització i l'administració. ARDIT LUCAS, 27 (2009): 295-316.

48. ARDIT LUCAS, 27 (2009): 305-312.

49. Aquests procediments estaven estrictament regulats pels furs com ja s'ha dit a la nota 19. Pel que respecta a la dificultat de que s'uniren la resta d'estaments, cal pensar 
De forma que, al igual que la Diputació d'Aragó uns mesos després, l'Estament Militar es sentia en l'obligació de referir al rei els seus arguments. Així com el duc de Villahermosa, ambaixador d'Aragó, escrivia sobre haver d'acudir al monarca que «es justo que nos hoyga y después delibere», de la mateixa manera ocorria amb els nobles valencians ja que no només estaven impulsats pels seus interessos estamentals i personals, sinó també per la obligació de consilium amb el seu senyor. No obstant, després de rebre l'argumentació del monarca i observar que la seua decisió estava ja presa, la fidelitat era l'única opció. Així que, finalment, el Braç militar es va oferir a col-laborar en la tasca de l'expulsió, però no va deixar de banda la seua funció de control sobre l'actuació de la Corona, tant per a procurar que l'actuació dels oficials reials no transgredís la legalitat com per a garantir que el monarca acomplís la seua paraula de compensar a la noblesa pels perjuís que l'expulsió els anava a produir. Per tant, podem concloure que, al menys en aquest cas, «ajustar-se ab la punctualitat y obediència acostumades a la voluntat del rey» no volia dir acceptar sense reserves l'actuació de la corona, sinó més bé intentar que una mesura ja inevitable causés el menor dany possible a l'Estament i al Regne.

\section{Apèndix documental}

1609 , setembre, 18 . València ${ }^{50}$

Memorial de l'Estament Militar demanant la suspensió de l'expulsió dels moriscos ARV, Real Cancillería, 527, ff. 402r.-407v.

Memorial per a sa magestat.

Senyor. Don Phelip Boïl de la Scala, senyor de Manises y don Joan Vallterra de Blanes, embaixadors de l'Stament Militar de la Ciutat y Regne de València. Prostrats humilment als reals peus de vostra magestat dihuen que per haver-se tengut noticia de la armada y altra gent de guerra de vostra magestat y de algunes prevencions y aparatos que es van fent en aquelles parts y per altres

que l'Eclesiàstic no estigués dispost, tant perquè l'arquebisbe Ribera participava en l'organització com perquè s'havia celebrat un concili amb els bisbes del regne que havia acordat la conveniència de l'expulsió.

50. Encara que en el document no s'observa la data, com s'exposa en el text sabem que va ser redactat en la reunió dels elets de l'Estament Militar de 18 de setembre de 1609 que tingué lloc en la Casa de la Diputació. 
intel-ligències que se han tengut y tenen lo dit estament militar per sa natura e fidelitat y per la grandíssima affectió y amor que tostemps ha tengut a la real corona se ha trobat constituit en precisa obligació de acudir al real conspecte de vostra magestat per medi de dits embaixadors a declarar y significar a vostra magestat que lo dit Stament militar y tots los singulars de aquell estan molt disposts y promptes per a servir ab ses persones, haziendes y vides en la present y altra qualsevol occasió que.s puga offerir del gust y servey de vostra magestat y augment de sa real corona. Emperò que per quant la communa veu y forma pública que se ha divulgat en aquell fidelíssim regne insurtida de moltes y molt provables coniectures intelligències y presentiments és que la real voluntat e intent de vostra magestat, per algunes justes $\left.\right|^{402 v}$ causes y respostes, seria i és de que los cristians nous sien extrets del dit regne y que a d'aquest fi y effecte van encaminats tots los dits aparatos y prevensions. No.s pot escusar lo dit Estament de significar a vostra magestat los irreparables danys, desdiches, afflictions y calamitats que forçoçament se han de seguir de la execució de semblant intent y resolució y per a que lo real animo de vostra magestat reste plenament informat dels dits danys per a que per sa innata clemència se incline a apiadar-se del dit regne manant suspendre y revocar la dita resolució ab la deguda y acostumada humilitat y summisió representen les coses següents: $\left.\right|^{403 r}$

1. Primerament que los pobles de christians nous del dit regne de València responen cascun any molts centenars de miliars de renda per via de carregaments de censals, les propietats dels quals importen nou o deu millons ans més que menys.

2. Ítem, que la dita renda és la major y més principal part del sustento així de la església major y de les dotze esglésies parroquials de dita ciutat en les quals resideixen a més de les dignitats y canonges més de 1200 beneficiats, ultra de més de 150 preveres capellans que no tenen benifets y sols se sustenten de la almoyna de les misses votives que.s celebren en diverses esglésies y confraries y de vint y cinch monestirs de frares en los quals hi ha més de 1250 religiosos, ${ }^{403 v}$ desset monestirs de monges ahon resideixen més de 850 religioses de vint y una confraries moltes de les quals acostumen cascun any diverses donzelles orfenes y pobres, de cinch espitals ço es lo espital general y altres quatre ahon se acudix ab molt gran compliment a la curació y remey 
de moltíssims pobres malalts així naturals com de altres parts y regnes, de collegis, set clausures de beates de diverses religions que vihuen retirades en servey de nostre senyor Déu, com també de moltes altres cathedrals, collegis, esglésies parrochials, convents y monestirs així de frares com de monges, confrares y reclusions de tot lo dit regne fora de dita ciutat ahon resideixen dicnitats, canonges, capellans, frares, monges y altres persones servents de Déu en número incomprehensible de moltíssimes viudes, pubils donzelles y altres particulars persones de tots estaments.

3. Ítem que si s'executàs la extracció dels dits nou convertits del dit regne que són los que fan que ponen los dits censals cessarien y expirarien aquells de hon se seguiria que totes les esglésies, convents, monestirs, capellans, frares, monges, $\left.\right|^{404 r}$ espitals, confraries y llochs pios mensionats en lo precedent capítol restarien totalment arruïnats y destruits y los religiosos y religioses forçosament haurien de deixar y desemparar sos convents y monestirs per no tenir remey de poder-se sustentar y viure y los sacrificis de misses y altres sufragis que.s fan per los deffuncts haurien de cessar, faltant, com faltaria, la ordinària renda y almoyna de dita celebració y la mateixa ruïna y destrucció patirien les vendes pubils y totes les demés persones mencionades en dit capítol que tenen ses rendes sobre los dits pobles.

4. Ítem, que de dita extracció resultarien també notabilíssims danys y pèrdues a innumerables cavallers y ciutadans y altres persones que viuhen de ses rendes pròpries les quals jatsia no tinguen censals carregats sobre les dites universitats de cristians nous emperò tenen molts censals y estan imposats especialment sobre los que responen dits pobles y tenen con- ${ }^{404 v}$ signacions de les pensions de aquells tots los quals censals y consignacions peririen y expirarien ab la dita extracció en irreparable dany de tantes persones.

5. Ítem, que en la industria y treball de dits nou convertits està de ordinari bastant provehit lo dit regne de forment, cevades, arròs, pances, figues, amelles, sucre, sedes y diverses altres vitualles y mercaderies de moltes de les quals se'n trahuen fora del dit regne per a provisió dels regnes circunvehins y altres de vostra magestat de hon ha resultat de ordinari grandíssim benefici y augment dels drets reals de vostra magestat, general y cises de dita ciutat y regne, tot lo qual rebria notabilíssima y casi total disminució y restarien impossibilitades així la casa de la generalitat de dit regne y la dita ciutat de 
València com les demés ciutats, viles y pobles del dit regne no sols de poder pagar los censals y altres carrechs que responen però encara de poder sustentar-ho $\left.\right|^{405 r}$ en manera alguna.

6. Ítem, que la major part dels mercaders y homens de negocis estan empleats en los arrendaments de tots los dits pobles y dels fruyts y emoluments de aquells y dels delmes y primícies de dits fruyts y per consegüent de la despopulació de aquells se seguiria necessàriament no collir-se fruyts alguns y per dita rahó cessarien los arrendaments y lo tracte y comerci general de tota la república.

7. Ítem, que no sols se perdria lo commerci referit en lo precedent capítol però encara lo tracte, exercici y ministeri de tots los artistes y oficials mecanichs en increïble dany de la cosa pública així perquè no y hauria faenes per als dits oficials com també perque seria difícil y casi impossible la cobrança de ses manufactures y treballs y de la mateixa manera faltarien faenes per a les dones que viuhen de son treball $\left.\right|^{405 v}$ y ajuden a sos marits en sos oficis que seris ocasió de moltíssims peccats y ofenses de nostre senyor Déu.

8. Ítem, per la depopulació de dits llochs de chistians nous haurien de cessar les 453 rectories de aquells y los rectors restarien desconsolats y sens tenir ab que passar ni viure.

9. Ítem que de la extracció dels dits cristians nous naixeria la total disminució així del archebisbat de València y bisbats suffraganeos de aquell com també dels delmes y terços delmes y primícies.

10. Ítem, que en lo dit regne de València hi ha diversos duchs, marquesos, comptes, barons y molts altres cavallers en número de més de 130 que són senyors de dits pobles de cristians nous dels quals ne fonch feta mercè a sos predecessors al temps de la conquista de dit regne en agraiment de in- $\left.\right|^{406 r}$ portantíssims serveys que havien fet a la real corona en lo discurs de dita conquista y que ab les rendes y emoluments dominicals de dits pobles se han sustentat fins ara conforme a sos estaments continuant tostemps la fidelitat y amor a la real corona heretada de sos passats com se ha vist per experiència en totes les ocasions que se han ofert del servey de sos reys y senyors en justa correspondència de la qual han rebut infinites mercès y senyaladament la que vostra magestat los feu de tenir-los per dignes y mereixedors de senyalar 
aquella ciutat per a la celebració y festes de son real casament ahon tenint-la y estimant-la en lo que tan senyalada mercè mereixia, se emplearen en procurar servir a vostra magestat y festejar un acte tan important y solemne ab totes les demostracions públiques de regosijo que'ls foren possibles ab la voluntat y amor de que vostra magestat fonch testimoni de vista del que ${ }^{406 v}$ per sa gran benignitat y grandesa mostra haver-ne restat molt satisfet y servit. Y així acostumats de rebre tantes mercès de la real mà de vostra magestat y dels sereníssims reys predecessors estan molt confiats y certs que vostra magestat per sa real clemència se servirà no donar lloch a la dita extracció dels nou convertits, la qual si se executàs restarien tots los dits senyors de pobles del tot arruinats y destruïts sens poder-se sustentar ni viure y impossibilitats de poder casar y acomodar a sos fills y filles, y ab contingència y casi certesa de haver de perir de fam. $\left.\right|^{407 r}$

11. Ítem, que per lo molt que importa a la utilitat y benefici universal de aquell regne que los cristians nous no ixquen de aquell ab aquesta rahó y causa final expressada no sols los sereníssims reys don Martí y don Alfonso tercer prometeren no permetres que los dits nous convertits ixquessen de dit regne sinó a terres de la sua senyoria y ab sa llicència segons és de veure en los capítols 33 y 34 sots títol de servis fugitivis, per açò encara en aprés lo sereníssim rey don Fernando en les corts celebrades en Oriola en lo any 1488 concedí que los dits cristians nus no ixquessen ni poguessen exir ni encara ab llicència ni havent comptat y pagat a sos senyors a ciutats, viles o llochs fora del dit regne encara que fossen de la sua senyoria segons resulta per lo fur 34 que és final del dit títol los quals furs y capítols són estats confermats y jurats per vostra magestat.

12. Ítem, se representa a vostra magestat que en temps de les comunitats los cristians nous de aquell regne se senyalaren molt de veres per la part dels imperials y assistiren, ajudaren y valgueren a sos amos y als demés cavallers y militars gallardament. Que tingueren molt principal part en la victoria que.s tingué dels agermanats y que al dia de hui resten encara moltes relíquies de la mala voluntat y avorriment que los cristians vells del poble conceberen llavors als nou convertits per la ocasió sobre dita. Y que així se deu recelar molt en la ocasió present de alguna alteració si.s volgués innovar en eixecutar la dita extractió. 
13. Finalment, és cosa certa que la conservació de dit regne principalment consistix en la del cristians nous, puix faltant aquells segons se ha dit y representat de necessitat y en conseqüència haurem de cessar tantes obres pies, sufragis de ànimes, esglésies, parròchies, convents, monestirs, espitals, confraries, destruir-se y arruinar-se tants títols, barons, cavallers, ciutadans, plebeyos, viudes y pubils. Los quals no sols deixaran de cobrar sos fruyts, rendes, emoluments y censals que al present cobren, tenen y reben sobre llochs de nou convertits y per ocasió y causa de aquells però també los demés censals que respectivament uns responen a altres y los que tenen en censals sobre la Gene- | | ${ }^{407 v}$ ralitat, ciutat de València y demés ciutats y viles reals del dit regne puix faltant-los la exactió y cobrança de ses properes rendes y a la generalitat ciutats y viles les de sos drets y cises de hon se paguen ha de cessar també la solusió y prestació de aquells.

De tot lo qual resulta que ab la dita extracció dels nous convertits se causaren los danys inconvenients, desdiches y treballs irremediables dessus referits. Tots los quals se escusarà manant vostra magestat que en açó no se innove cosa alguna com ho confia lo dit Estament Militar de la gran cristiandat y clemència de vostra magestat.

\section{Bibliografia}

Álvarez-Ossorio Alvariño, Antonio, «Ceremonial de palacio y constitución de monarquía: las embajadas de las provincias en la corte de Carlos II», Annali di Storia moderna e contemporanea, 6 (2000): 227-358.

ARDIT LUCAS, Manuel, «Una reflexión sobre la expulsión de los moriscos valencianos y repoblación», Revista de Historia Moderna. Anales de la Universidad de Alicante, 27 (2009): 295-316. http://dx.doi.org/10.14198/RHM2009.27.12

BENítez SÁNCHEZ-BLANCO, Rafael, «Fueros y razón de estado en torno a la expulsión de los moriscos y el problema de la repoblación del Reino de Valencia» en Remedios Ferrero Micó i Lluís Guia Marín (Eds.), Corts i Parlaments de la Corona d'Aragó. Unes institucions emblemàtiques en una monarquia composta, València, Universitat de València, 2008: 223-238.

BENÍTEZ SÁNCHEZ-BLANCO, Rafael, «La representación del Reino de Valencia fuera de Cortes: la embajada del marqués de Benavites y las armas del Reino», Saitabi, 60-61 (2010-2011): 303-325. Disponible en: http://roderic.uv.es/ handle/10550/27332 [comprovat a 13 de juny de 2018] 
Benítez SÁnCHEZ-Blanco, Rafael, Tríptico de la expulsión de los moriscos: el triunfo de la razón de estado, Montpellier, Presses Universitaires de la Méditerranée, 2012.

Bernabé Gil, David, El municipio en la Corte de los Austrias. Sindicos y embajadas de la ciudad de Orihuela en el siglo XVII, València, Institució Alfons el Magnànim, 2007.

BERNABÉ GIL, David, «Las embajadas municipales como ámbito de relación política con la corona al margen de las Cortes» en Remedios Ferrero Micó i Lluís Guia Marín (Eds.), Corts i Parlaments de la Corona d'Aragó. Unes institucions emblemàtiques en una monarquia composta. València, Universitat de València, 2008: 429-444.

CANET APARISI, Teresa, La magistratura valenciana (s. XVI-XVII), València, Universitat de València, 1990.

CASEY, James, «Las causas económicas de la expulsión de los moriscos», Revista de Historia Moderna. Anales de la Universidad de Alicante, 27 (2009): 135-150. http://dx.doi.org/10.14198/RHM2009.27.05

Castillo Del CARPIO, José M., La Generalidad valenciana durante el siglo XVI. Su estructura burocrática, sus competencias, sus hombres, València, Universitat de València, 2013.

Ciscar PAllarÉs, Eugenio, «Economía y fiscalidad en los señoríos pobres de la casa de Gandía en la época de la expulsión de los moriscos», Revista de Historia Moderna. Anales de la Universidad de Alicante, 24 (2006): 123-152. http://dx.doi.org/10.14198/RHM2006.24.04

Clavell LóPEZ, Oscar, Funciones de la Generalidad durante la época moderna. La representatividad del reino fuera de Cortes, Treball final de màster, València, Universitat de València, 2016.

Escolano, Gaspar, Segunda parte de la década primera de la historia de la insigne y coronada Ciudad y Reyno de Valencia, Valencia, Pedro Patricio Mey, 1611. Disponible en: http://bivaldi.gva.es/es/consulta/registro.cmd?id=9357 [comprovat a 13 de juny de 2018]

FONSECA, Damián, Iusta expulsión de los moriscos de España. Con la instrucción, apostasía y trayción dellos; y respuesta a las dudas que se ofrecieron acerca desta materia, Roma, Iacomo Mascardo, 1612. Disponible en: http://bivaldi.gva.es/ es/consulta/registro.cmd?id=3204 [comprovat a 13 de juny de 2018]

Fuertes Broseta, Miquel, «Lambaixada del senyor de Gilet (1655-1656). La relació de la monarquia i el regne de València a mitjans del segle XVII», Estudis: 
Revista de historia moderna, 42 (2016): 249-264. Disponible: http://roderic. uv.es/handle/10550/63352 [comprovat a 13 de juny de 2018]

GIMÉNEZ CHORNET, Vicent, «La representatividad política en la Valencia foral», Estudis: Revista de historia moderna, 18 (1992): 7-28. Disponible en: https:// www.uv.es/dep235/PUBLICACIONS_II/PDF86.pdf [comprovat a 13 de juny de 2018]

Guia Marín, Lluís J., «La Junta de Contrafurs: uns inicis conflictius», Saitabi, 42 (1992): 33-45. Disponible en: http://roderic.uv.es/handle/10550/27051 [comprovat a 13 de juny de 2018]

GUIA MARÍn, Lluís J., "A la cerca de l'horitzó: la noblesa valenciana i l'ambaixada del senyor de Borriol de 1654», Saitabi, 51-52 (2001-2002): 315-335. Disponible en: http://roderic.uv.es/handle/10550/27218 [comprovat a 13 de juny de 2018]

Guia Marín, Lluís J., «El Regne de València. Pràctica i estil parlamentaris», Ius fugit, 10-11 (2001-2002): 889-933.

HALPERIN DONGHI, Tulio, Un conflicto nacional: moriscos y cristianos viejos en Valencia, València, 2008.

LA PARRA LóPEZ, Santiago, «1609 en el Ducado de Gandía», Estudis. Revista de historia moderna, 16 (1990): 217-232. Disponible en: http://roderic.uv.es/ handle/10550/34190 [comprovat a 13 de juny de 2018]

LAPEYRe, Henry, Geografía de la España morisca, València, Diputació Provincial de València, 1986.

LOMAS CORTÉs, Manuel, La expulsión de los moriscos del Reino de Aragón. Política y administración de una deportación (1609-1611), Teruel, Centro de Estudios Mudéjares, 2008.

LOMAS CORTÉS, Manuel, «Innata fidelitat i notable desconsol. La integració de la noblesa valenciana en el procés d'expulsió dels moriscos», Afers, fulls de recerca i pensament, 62/63 (2009): 127-150.

LOMAS CORTÉS, Manuel, El proceso de expulsión de los moriscos de España (16091614), Valencia/Granada/Zaragoza, Universitat de València/Universidad de Granada/Prensas Universitarias de Zaragoza, 2011.

Lorite Martínez, M. Isabel, Pactismo y representación del Reino: las juntas del Estamento Militar de Valencia (1488-1598), Tesis doctoral, València, 2015. Disponible en: http://roderic.uv.es/handle/10550/50529 [comprovat a 13 de juny de 2018] 
MARTíNEZ, François, La permanence morisque en Espagne après 1609 (discurs et réalités), Tesis doctoral, Montpellier, Université de Montpellier-2, 1997.

MARTínEZ BARA, José Antonio, «'Missatgeria' enviada a Felipe II en 1586 por el reino valenciano», en VIII Congreso de Historia de la Corona de Aragón. Vol. III-2: La Corona de Aragón en el siglo XVI, València, Caja de Ahorros y Monte de Piedad de Valencia, 1973: 197-214.

Mateu i SAnZ, Llorenç, Tratado de la celebración de Cortes Generales del Reino de Valencia, Madrid, Julián de Paredes, 1677. Disponible en: http://bivaldi. gva.es/es/consulta/registro.cmd?id=3258 [comprovat a 13 de juny de 2018]

PÉREZ APARICIO, Carme, «Centralisme monàrquic i resposta estamental: l'ambaixada valenciana del senyor de Cortes (1667-1668)», Pedralbes, 13-1 (1993): 327-340.

Salvador Esteban, Emilia, Cortes Valencianas del Reinado de Felipe II, València, Universitat de València, 1972.

SALVADOR ESTEBAN, Emilia «Un ejemplo de pluralismo institucional en la España moderna. Los estamentos valencianos», en Homenaje a Antonio de Béthencourt Massieu, Vol. 3, Gran Canaria, Cabildo de Gran Canaria, 1995: 347-365.

SALVADOR ESTEBAN, Emilia, «La cuestión de los censales y la expulsión de los moriscos valencianos», Estudis: Revista de historia moderna, 24 (1998): 127 146. https://www.uv.es/dep235/PUBLICACIONS_III/PDF57.pdf [comprovat a 13 de juny de 2018]

SAlVAdor Esteban, Emilia «Las Juntas de Estamentos en la Valencia foral moderna. Notas sobre su extinción», en Josep Fontana Història i Projecte social. Reconeiximent a una trajectòria, Barcelona, Crítica, 2004: 370-385. 